\title{
10.2: Garnet Phosphors Prepared via Hydrothermal Synthesis
}

\author{
Mark L. F. Phillips, " Robert J. Walko, and Lauren E. Sheat \\ Sandia National Laboratories, Albuquerque, NM 87185
}

\begin{abstract}
This project studied hydrothermal synthesis as a route to producing green-emitting cathodoluminescent phosphors isostructural with yttrium aluminum garnet $\left(\mathrm{Y}_{3} \mathrm{Al}_{5} \mathrm{O}_{12}\right.$, or YAG). Aqueous precipitation of $\mathrm{Y}, \mathrm{Gd}, \mathrm{Al}$, $\mathrm{Ga}$, and $\mathrm{Tb}$ salts produced amorphous gels, which were heated with water at $600{ }^{\circ} \mathrm{C}$ and 3200 bar to produce crystalline YAG:Tb, $\mathrm{Y}_{3} \mathrm{Ga}_{5} \mathrm{O}_{12}: \mathrm{Tb}, \mathrm{Y}_{3} \mathrm{Al}_{3} \mathrm{Ga}_{2} \mathrm{O}_{12}: \mathrm{Tb}$, and $\mathrm{Gd}_{3} \mathrm{Ga}_{5} \mathrm{O}_{12}$ : $\mathrm{Tb}$ powders. Process parameters were identified that yielded submicron YAG:Tb and $\mathrm{Y}_{3} \mathrm{Ga}_{5} \mathrm{O}_{12}$ : $\mathrm{Tb}$ powders without grinding. Cathodoluminescent efficiencies were measured as functions of power density at $600 \mathrm{~V}$, using both the hydrothermal garnets and identical phosphor compositions synthesized at high temperatures. Saturation behavior was independent of synthetic technique, however, the hydrothermal phosphors were less susceptible to damage (irreversible efficiency loss) at very high power densities (up to $0.1 \mathrm{~W} / \mathrm{cm}^{2}$ ). The fine grain sizes available with hydrothermal synthesis make it an attractive method for preparing garnet phosphors for field emission, projection, and head-up displays.
\end{abstract}

\section{Introduction}

Field emission-based displays (FEDs) are emerging as alternatives to liquid crystal displays in direct-view flat panel display applications. FEDs use electron beams to excite cathodoluminescent (CL) phosphors deposited on a screen, as do conventional cathode ray tubes (CRTs). However, FEDs emit electrons from arrays of microscopic cold cathodes, rather than from thermionic electron guns such as those used in CRTs. Because the individual electron beams cannot be steered, the emitter array must be placed close to the phosphor screen (ca. $40-100 \mu \mathrm{m})$ to maintain adequate resolution. The emitter cathodes must therefore be operated at low voltages, potentially between 5 and $500 \mathrm{~V}$, to avoid vacuum breakdown, which can occur at potential gradients in excess of $10^{5} \mathrm{~V} / \mathrm{cm} .1$

* Author to whom correspondence should be addressed. † Current address: Materials Science Program, University of California, San Diego; La Jolla, CA 92093.

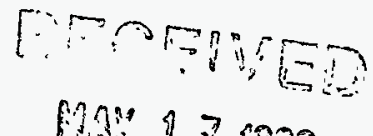

The low electron energies, high beam currents, and $7 x$ short cathode-screen distances in FEDs place new demands on phosphor screens. These demands are not well addressed by screens optimized for high energy $\mathrm{C} L$ displays such as CRTs. Phosphors for FED screens must be efficient at low voltages, and resistant to saturation and Coulomb aging at high current densities. Additionally, the phosphors must not contaminate the atmosphere within the FED by releasing volatile components. Other desirable characteristics include high chromatic saturation, short-to-medium persistence, electrical conductivity, and availability as fine-grained powders with a narrow size distribution. Improvements in saturation characteristics, damage resistance and grain size distribution would also benefit projection television and head-up displays, which require high screen brightness and resolution. ${ }^{2}$

Phosphors under consideration for use in FEDs include $\mathrm{ZnS}: \mathrm{Ag}, \mathrm{Cl}, \mathrm{ZnS}: \mathrm{Cu}, \mathrm{Al}$, and $\mathrm{Y}_{2} \mathrm{O}_{2} \mathrm{~S}: \mathrm{Eu}$, which are used as the blue, green, and red elements in color television, respectively. Unfortunately, under certain conditions sulfide phosphors can generate sulfurcontaining gases, which in turn can contaminate emitter cathodes. 3 Oxide phosphors are preferable from a contamination standpoint, but the CL efficiencies of these materials are generally lower than those of sulfides. Reduced zinc oxide $(\mathrm{ZnO}: \mathrm{Zn})$ is unusual among oxide phosphors in that it is both efficient at low voltages (as low as $5 \mathrm{~V}$ ) and electrically conductive, 4 and it is being widely studied as a greenemitting phosphor for FEDs. However, the temperature sensitivity, and poor chromaticity and saturation characteristics of $\mathrm{ZnO}: \mathrm{Zn}$ render it less than ideal in this application. In contrast, green-emitting garnet phosphors such as $\mathrm{Y}_{3} \mathrm{Al}_{5} \mathrm{O}_{12}$ : $\mathrm{Tb}$ (YAG:Tb) display good chromaticity, and high resistance to saturation and degradation at high power densities. These phosphors have efficiencies comparable to or greater than $\mathrm{ZnO}: \mathrm{Zn}$ at moderate voltages (200-1000 V). 5

YAG:Tb and related garnet phosphors such as $\mathrm{Y}_{3} \mathrm{Al}_{3} \mathrm{Ga}_{2} \mathrm{O}_{12}: \mathrm{Tb}$ (YAGG:Tb) are usually synthesized directly from the constituent oxides or oxide precursors at high temperatures $\left(>1200^{\circ} \mathrm{C}\right) .6^{6}$ This process produces grains several micrometers in diameter. These particles can be further reduced by grinding, but this can cause surface contamination and defects, decreasing efficiency. ${ }^{7}$ Hydrothermal synthesis has been used to 


\section{DISCLAIMER}

Portions of this document may be illegible in electronic image products. Images are produced from the best available original document. 
produce fine grained ceramic powders without grinding, and hydrothermal routes have been reported for several oxide phosphors or phosphor host phases, including $\mathrm{Zn}_{2} \mathrm{SiO}_{4}: \mathrm{Mn}, 8 \mathrm{YVO}_{4}: \mathrm{Eu}, 9$ and $\mathrm{Y}_{3} \mathrm{Al}_{5} \mathrm{O}_{12}: \mathrm{Tb}^{10}$

We have previously shown that this approach can be used to generate submicron YAG:Tb powders with $\mathrm{CL}$ characteristics similar to those of YAG:Tb prepared via conventional means. ${ }^{11}$ We have since broadened this study to include garnet phosphors isostructural with YAG:Tb, in particular, $\mathrm{Y}_{3} \mathrm{Al}_{3} \mathrm{Ga}_{2} \mathrm{O}_{12}$ : $\mathrm{Tb}$ (YAGG:Tb), $\mathrm{Y}_{3} \mathrm{Ga}_{5} \mathrm{O}_{12}: \mathrm{Tb}$ (YGG:Tb), and $\mathrm{Gd}_{3} \mathrm{Ga}_{5} \mathrm{O}_{12}$ (GGG:Tb). We report here the hydrothermal synthesis of these phases for the first time, and discuss the effects of hydrothermal and high-temperature processing on $\mathrm{CL}$ parameters that are relevant to field emission displays.

\section{Experimental}

The YAG:Tb, YGG:Tb, GGG:Tb, and YAGG:Tb phosphors were synthesized hydrothermally by dissolving $\mathrm{Y}\left(\mathrm{NO}_{3}\right)_{3} \cdot 4 \mathrm{H}_{2} \mathrm{O}$ or $\mathrm{Gd}\left(\mathrm{NO}_{3}\right)_{3} \cdot 6 \mathrm{H}_{2} \mathrm{O}$ (Aldrich) with $\mathrm{Tb}\left(\mathrm{NO}_{3}\right)_{3} \cdot 5 \mathrm{H}_{2} \mathrm{O}$ (Johnson Matthey), $\mathrm{AlCl}_{3} \cdot 6 \mathrm{H}_{2} \mathrm{O}$ (Baker) and/or $\mathrm{Ga}\left(\mathrm{NO}_{3}\right)_{3} \cdot 9 \mathrm{H}_{2} \mathrm{O}$ (Aldrich) in water, then adding $27 \%$ aqueous $\mathrm{NH}_{3}$ (Fisher) until a pH of 10 was reached. The resulting gels were then centrifuged, rinsed, dried at $175^{\circ} \mathrm{C}$, and heated at $500{ }^{\circ} \mathrm{C}$ for $12 \mathrm{~h}$ in flowing $\mathrm{O}_{2}$. This yielded amorphous precursors that were then ground, individually welded in Au tubes with an equivalent weight of water, and autoclaved at $600^{\circ} \mathrm{C}$ and $3.2 \mathrm{MPa}$. Products were recovered by filtration, using Gelman $0.22 \mu \mathrm{m}$ membrane filters, then annealed at $1200^{\circ} \mathrm{C}$.

YAG:Tb, YGG:Tb, and GGG:Tb powders were also synthesized via direct solid state reactions. $\mathrm{Y}_{2} \mathrm{O}_{3}$ or $\mathrm{Gd}_{2} \mathrm{O}_{3}$ (Aldrich), $\mathrm{Tb}\left(\mathrm{NO}_{3}\right)_{3} \cdot 5 \mathrm{H}_{2} \mathrm{O}$, and $\gamma-\mathrm{Al}_{2} \mathrm{O}_{3}$ (Ceralox) or $\mathrm{Ga}_{2} \mathrm{O}_{3}$ (Fluka) were combined in stoichiometric proportions, pre-reacted at $1200^{\circ} \mathrm{C}$ for $18 \mathrm{~h}$, reground, and annealed at $1450^{\circ} \mathrm{C}$ for $6 \mathrm{~h}$.

The purity of all phases was established by powder Xray diffraction, using an Siemens D-500 diffractometer ( $\mathrm{Cu} \mathrm{K} \alpha$ radiation, $\lambda=1.54059 \AA$ ). Particle sizes were determined by scanning electron microscopy (SEM) and by sedimentation. Samples for SEM were sputtered with $\mathrm{Au}$, and analyzed using an AMRAY model 1645 electron microscope. Particle size determination by sedimentation was performed by suspending the powder samples in a 1 weight percent aqueous sodium hexametaphosphate solution or in ethylene glycol, sonicating, and measuring settling rates using a Horiba CAPA-700 particle size analyzer.

Cathodoluminescence data were collected from samples apcked approximately $1 \mathrm{~mm}$ deep into stainless steel cups. The samples were installed in a vacuum chamber, which was evacuated to a pressure of less than $5 \times 10^{-6}$ $\mathrm{Pa}$. A hot filament, low energy electron gun (Kimball Physics) was the source of the beam, which was steered and focused using external Helmholtz coils. During analysis the sample cup or screen surface was maintained at a potential of $+100 \mathrm{~V}$ with respect to ground. The electron beam was focused onto a spot 5.6 $\mathrm{mm}$ in diameter. Luminous intensity and chromaticity of the light emitted from the sample was measured with a Minolta CS -100 photometer.

\section{Results}

$Y A G: T b$ As a result of hydrothermal processing, the amorphous precursor gel crystallized to form a pure YAG:Tb powder. This powder consisted of garnetshaped YAG:Tb crystallites with particle diameters between 0.2 and $2 \mu \mathrm{m}$ (Figure 1), and a median particle diameter of $0.55 \mu \mathrm{m}$. These crystallites showed little tendency to agglomerate, and could be readily suspended in water through sonication.

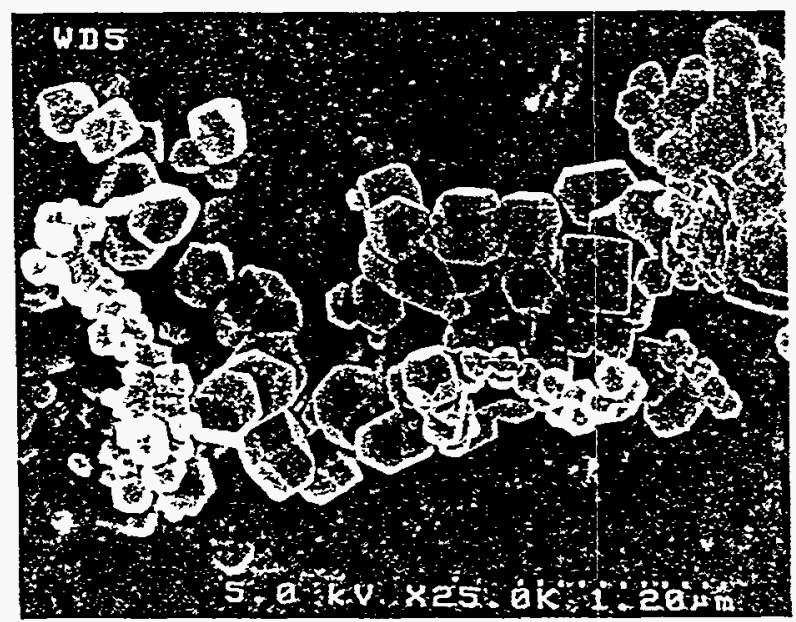

Figure 1: Hydrothermally synthesized YAG:Tb crystallites. Scale bar $=1.20 \mu \mathrm{m}$.

Portions of the YAG:Tb powders were annealed at 1200 ${ }^{\circ} \mathrm{C}$ and at $1450{ }^{\circ} \mathrm{C}$ for several hours. After annealing at $1200^{\circ} \mathrm{C}$, most crystallites remain intact, but those smaller than $0.1 \mu \mathrm{m}$ sinter together. At $1450^{\circ} \mathrm{C}$, crystallites of all sizes begin to sinter together to yield a powder with a coarse, grainy texture as seen in SEM, but no additional improvement in CL efficiency is observed.

Cathodoluminescent efficiency data were measured as a function of power density for both solid state synthesized and hydrothermally synthesized YAG:Tb phosphors (Figure 2). This was accomplished by increasing the electron beam current at constant voltage to a maximum, then decreasing the current, while 


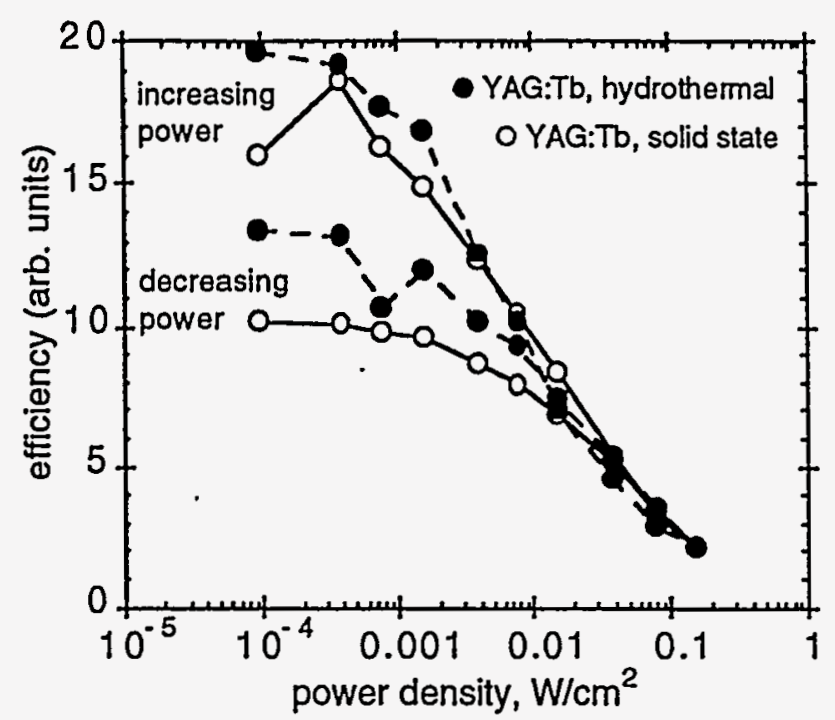

Figure 2: $\mathrm{CL}$ saturation/burn data for YAG:Tb phosphors at $600 \mathrm{~V}$.

maintaining the beam in the same position on the phosphor sample. These data show that the phosphors saturate at high power densities (up to $0.15 \mathrm{~W} / \mathrm{cm}^{2}$ ), and that the solid state and hydrothermal powders saturate to a similar extent. However, the annealed hydrothermal phosphors sustained less permanent damage, as measured by loss of low-power efficiency, than those prepared by conventional solid state reaction. It is possible that the better-faceted hydrothermal YAG:Tb crystallites distribute heat and surface charge more evenly, reducing the number and intensity of hot spots.

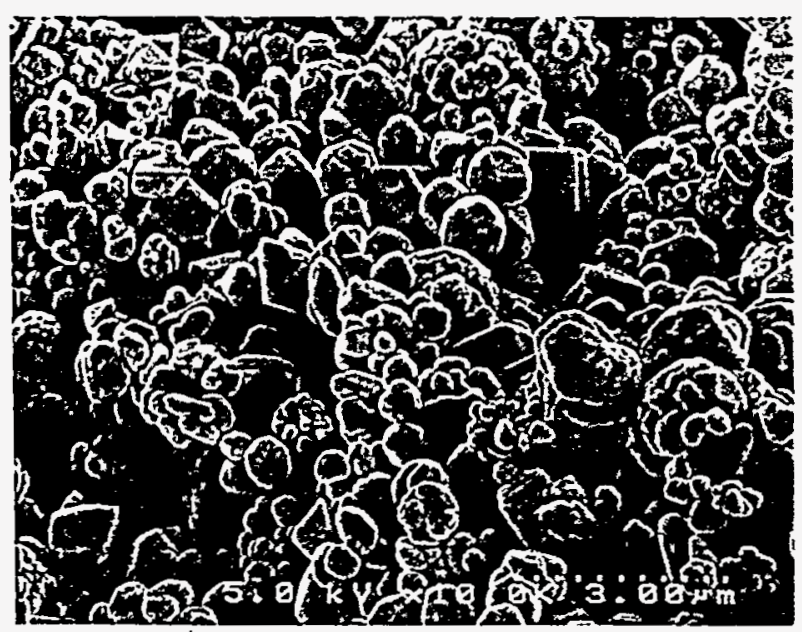

Figure 3: Hydrothermally synthesized YGG:Tb powder. Scale bar $=3 \mu \mathrm{m}$.

YGG:Tb The hydrothermal process also yielded pure $\mathrm{Y}_{3} \mathrm{Ga}_{5} \mathrm{O}_{12}: \mathrm{Tb}$ powder, but the garnet morphology of these grains is less distinct (Figure 3 ). This is consistent with mild over-nucleation of the starting gel, indicating that the gel had been pre-fired at an excessively high temperature. The particle size distribution is similar to that of YAG:Tb, with a median diameter of $1.0 \mu \mathrm{m}$. CL saturation and damage data were acquired in the same fashion as for YAG:Tb (Figure 4). While the sample of YGG:Tb prepared hydrothermally is generally less efficient than the sample synthesized at high temperature, the former appears more resistant to saturation at moderate power densities. In addition, the hydrothermal sample retains a larger fraction of its original efficiency after exposure to maximum beam power; this is consistent with the YAG:Tb results. It is possible that incomplete annealing may explain the lower initial CL efficiency of the hydrothermally prepared material.

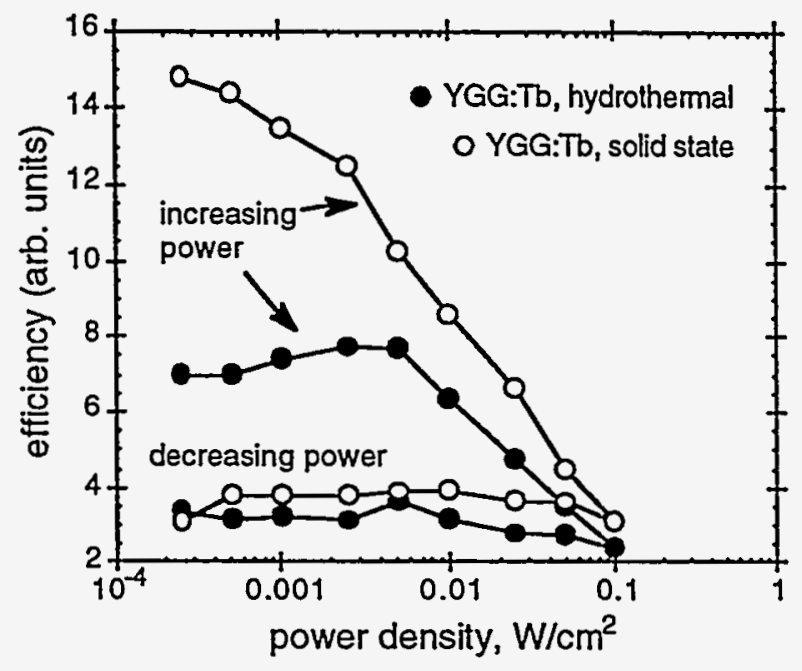

Figure 4: CL saturation/burn data for YGG:Tb phosphors at $600 \mathrm{~V}$.

The 1931 CIE chromaticity coordinates changed slightly as the power density was increased, but nemissio generally remained a well-saturated green. The starting values of $x=0.351, y=0.527$ (solid state) and $x=0.350, y=0.525$ (hydrothermal) decreased to $x=0.353$, $y=0.517$ (solid state) and $x=0.343, y=0.523$ (hydrothermal) at maximum current density. The chromaticity coordinates reverted to their original values as the current density was reduced.

YAGG:Tb The hydrothermal process yielded grains of $\mathrm{Y}_{3} \mathrm{Al}_{3} \mathrm{Ga}_{2} \mathrm{O}_{12}$ :Tb with a garnet habit (Figure 5) and a median particle diameter of $17 \mu \mathrm{m}$. CL saturation and damage data for this material are compared with those of a commercial sample of YAGG:Tb (Phosphor Technology Ltd.) in Figure 6. While the saturation behaviors are similar, the CL efficiency of the hydrothermal sample is generally twice that of the 
commercial material, though the larger grain size may be partially responsible. The chromaticity coordinates changed reversibly with current density in a manner similar that seen in YGG:Tb.

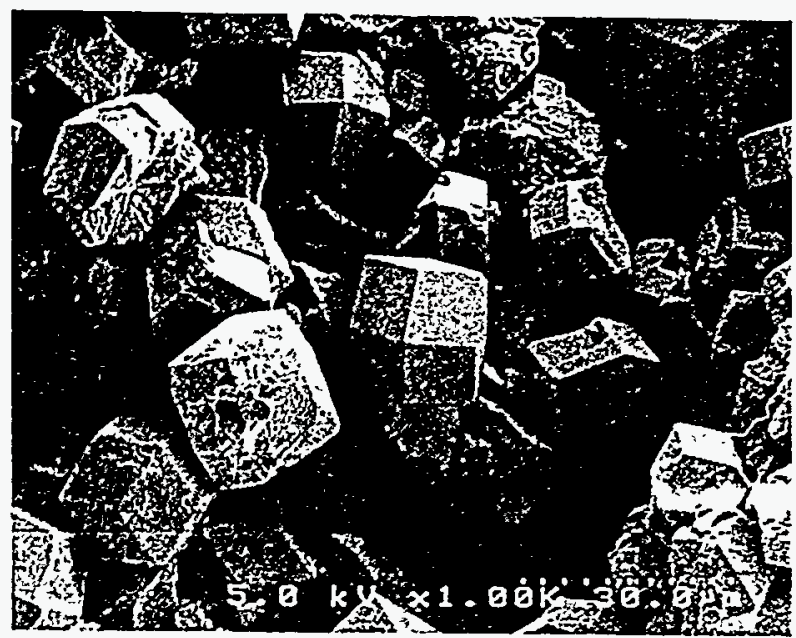

Figure 5: Hydrothermally synthesized YAGG:Tb grains. Scale bar $=30 \mu \mathrm{m}$.

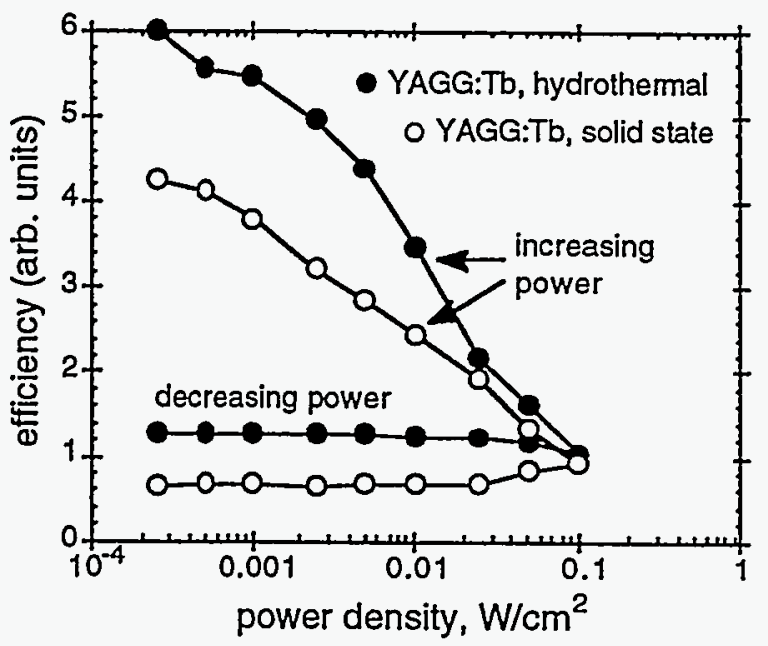

Figure 6: CL saturation/burn data for YAGG:Tb phosphors at $600 \mathrm{~V}$.

GGG:Tb Gel compositions that yielded pure GGG:Tb upon hydrothermal treatment were identified, but the particle morphology is indistinct, with a median particle size of $3.2 \mu \mathrm{m}$. It is likely that the starting gels become over-nucleated at a firing temperature of $500{ }^{\circ} \mathrm{C}$. The $\mathrm{CL}$ data for GGG:Tb follow the same trend as those for YGG:Tb, specifically, the samples synthesized at high temperature are initially more efficient, but the hydrothermal samples retain a larger proportion of their initial efficiency.

\section{Discussion}

The fine grain sizes available with hydrothermal synthesis make it an attractive and enhanced method for preparing garnet phosphors for display applications where particle size is an issue. The particle size distribution can be controlled to a certain extent by altering process parameters. These parameters have nearly been optimized in the case of YAG:Tb and YGG:Tb synthesis, and are under study in YAGG:Tb and GGG:Tb. Small grain sizes facilitate electrophoretic deposition of screens for field emission displays, and increase resolution in projection and headup display screens. These high-brightness displays may also benefit from the enhanced damage resistance of hydrothermal garnet phosphors. The CL results in this work suggest that terbium-doped garnets are efficient enough at moderate voltages $(200-1000 \mathrm{~V})$ to merit serious consideration as alternatives to $\mathrm{Gd}_{2} \mathrm{O}_{2} \mathrm{~S}$ : $\mathrm{Tb}$ and $\mathrm{ZnO}: \mathrm{Zn}$ in field emission displays.

\section{Acknowledgments}

This work was supported by the U. S. Department of Energy under contract no. DE-AC04-94AL 85000. The contributions of Robert Mays, Bonnie McKenzie, Gary Zender, and Diana Lamppa are appreciated.

\section{References}

1. I. Brodie and C. A. Spindt in P. W. Hawkes, ed., Advances in Electronics and Electron Physics, Vol. 83, Academic Press, San Diego, 1992, pp. 1-106.

2. R. Raue, A. T. Vink, and T. Welker, Philins Tech. Rev. 44 (11/12), 335-347 (1989).

3. S. Itoh, T. Kimizuka, and T. Tonegawa, $J$. Electrochem. Soc. 136(6), 1819-1823 (1989).

4. a. K. Narita, A. Kagami, and Y. Mimura, J. Electrochem. Soc. 1794-98 (1980). b. A. O. Dmitrienko and S. L. Shmakov, Inorganic Materials 30(4), 534-5 (1994).

5. R. Mays, R. J. Walko, and M. L. F. Phillips, unpublished results.

6. R. C. Ropp, The Chemistry of Artificial Lighting Devices, Elsevier: Amsterdam, 1993, p. 502.

7. S. Itoh, T. Tonegawa, T. L. Pykosz, K. Morimoto, and H. Kukimoto, J. Electróchem. Soc. 134 (12), 3178-3181 (1987).

8. T. Takahashi, Japanese Patent 63,196,683 (1988).

9. R. C. Ropp and B. Carroll, J. Inorg. Nucl. Chem. 39, 1303-7 (1977).

10. T. Takamori and L. D. David, Am. Ceram. Soc. Bull. 65 (9), 1282-1286 (1986).

11. M. L. F. Phillips and B. G. Potter, Proceedings of the ACerS Symposium on the Synthesis and Application of Lanthanide-doped Ceramics, Crystals and Glasses, American Ceramic Society: Westerville, $\mathrm{OH}, 1996$, in press. 


\section{DISCLAIMER}

This report was prepared as an account of work sponsored by an agency of the United States Government. Neither the United States-Government nor any agency thereof, nor any of their employees, makes any warranty, express or implied, or assumes any legal liability or responsibility for the accuracy, completeness, or usefulness of any information, apparatus, product, or process disclosed, or represents that its use would not infringe privately owned rights. Reference herein to any specific commercial product, process, or service by trade name, trademark, manufacturer, or otherwise does not necessarily constitute or imply its endorsement, recommendation, or favoring by the United States Government or any agency thereof. The views and opinions of authors expressed herein do not necessarily state or reflect those of the United States Government or any agency thereof. 